\title{
Vigilância em saúde aplicada em unidades revendedoras de combustível: estudo sobre ambiente e segurança do trabalho
}

\section{Francisco Bruno Monte Gomes ${ }^{1, *}$, Ahmad Saeed Khan ${ }^{1}$, Marcus Vinicius Freire Andrade ${ }^{2}$, Suely Torquato Ribeiro $^{3}$ e Maria Alcilene Morais ${ }^{1}$}

${ }^{1}$ Universidade Federal do Ceará. Centro de Ciências. Bloco 902. Campus do Pici. Fortaleza-CE, Brasil (CEP 60455-970). *E-mail: bruno06gomes@gmail.com.

${ }^{2}$ Intituto Federal de Educação, Ciência e Tecnologia do Ceará. Campus de Sobral. Av. Dr. Guarani, 317. Derby Clube. Sobral-CE, Brasil (CEP 62042-030).

${ }^{3}$ Prefeitura Municipal de Sobral. Vigilância em Saúde Ambiental. Rua Viriato de Medeiros, 1250. Centro. Sobral-CE, Brasil (CEP 62011-065).

Resumo. As unidades revendedoras de combustíveis derivados de petróleo se caracterizam como uma atividade potencialmente poluidora, tanto do ponto de vista ambiental, quanto de saúde das populações que vivem na sua zona de influência. Com isso, o alinhamento de estudos em monitoramento por ambos os setores são de extrema importância. Assim, o presente estudo objetivou avaliar em 38 postos de combustíveis, localizados no Município de Sobral, Estado do Ceará, nordeste do Brasil, os níveis de exposição a contaminantes químicos de populações e, posteriormente, descrevendo um prévio diagnóstico realizado por equipe técnica de saúde do trabalho sobre os graus de possíveis agressões a saúde dos trabalhadores ao desenvolverem suas funções. A pesquisa foi realizada entre os anos de 2018 e 2019 , contou com uma equipe multidisciplinar sob representação da Vigilância em Saúde Ambiental e em Saúde do Trabalhador do município, optou-se por utilizar uma metodologia baseada na condução técnica definida pelo Programa do Ministério da Saúde VIGISOLO e complementado por vistorias técnicas in loco. Foi possível concluir ao longo dos levantamentos que as populações que residem nas proximidades de até $1 \mathrm{~km}$ dos postos, estão em caráter suspeito de possíveis contaminações; esses fatores se elevam principalmente nas zonas rurais, onde contatou-se em vários pontos o descarte irregular de subprodutos oriundos das atividades, é necessário também que haja uma maior integração entre outros órgãos, para assim poder aprofundar de forma mais técnica até que ponto essas alterações podem causar. Em relação a saúde ocupacional dos trabalhadores ainda há fragilidades nos processos de cuidado com prevenção, evidenciando que os gestores devem intensificar ações internas de monitoramento e acompanhamento.

Recebido

$13 / 06 / 2021$

Aceito

08/08/2021

Disponível on line $11 / 08 / 2021$

Publicado

$31 / 08 / 2021$

Acesso aberto

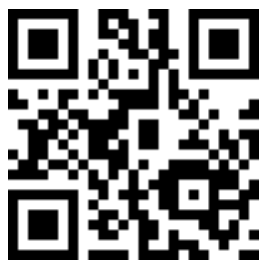

(D) $0000-0002-5703-627 \mathrm{X}$

Francisco Bruno Monte Gomes

D) 0000-0002-4079-7574 Ahmad Saeed Khan

ISSN 2359-1412/RBGAS-2021-0073/2021/8/19/29/1061

Rev. Bras. Gest. Amb. Sustent.

http://revista.ecogestaobrasil.net 
Palavras-chave: Contaminantes; Populações; Riscos; Saúde; Vigilância ambiental.

Abstract. Health surveillance applied to fuel reseller units: $A$ study on work environment and safety. Oil-derived fuel reseller units are characterized as a potentially polluting activity, both from an environmental point of view, as well as the health of the populations living in their area of influence. Thus, the alignment of studies being monitored by both sectors is extremely important. Therefore, the present study aimed to evaluate at 38 gas stations located in the Municipality of Sobral, State of Ceará, Northeast Brazil, the levels of exposure to chemical contaminants of populations and, subsequently, describing a previous diagnosis carried out by a technical occupational health team on the degrees of possible aggressions to workers' health when performing their functions. The research was carried out between 2018 and 2019, with a multidisciplinary team represented by the municipality's Environmental Health and Occupational Health Surveillance. We chose to use a methodology based on the technical conduct defined by the Brazilian Ministry of Health Program VIGISOLO and complemented by technical inspections in loco. It was possible to conclude throughout the surveys that the populations that reside in the vicinity of up to $1 \mathrm{~km}$ from the posts are suspicious of possible contamination; these factors rise mainly in rural areas, where irregular disposal of by-products from activities was contacted at various points, it is also necessary that there is greater integration between other bodies, in order to be able to deepen more technically the extent to which these changes can cause. Regarding the occupational health of workers, there are still weaknesses in the care processes with prevention, showing that managers must intensify internal monitoring and follow-up actions.

Keywords: Contaminants; Populations; Risks; Health; Environmental surveillance.

\section{Introdução}

A poluição mundial está cada vez mais preocupante e proporcionado alerta para a população. Inúmeras técnicas vêm sendo utilizadas no intuito de minimizar ou prevenir danos severos no ecossistema, pois as contaminações, a depender da intensidade, afetam diretamente a atmosfera, solo, florestas, animais, rios e oceanos. Diante da execução destas técnicas o setor de saúde pública tem tido um papel fundamental, da qual, tem organizado com muito cuidado os caminhos para executar essas práticas.

Primeiramente, identificar as populações com elevado potencial de exposição constitui uma etapa importante no processo de elaboração de programas preventivos e de avaliação da vulnerabilidade, já que a localização destas populações no espaço permite um maior detalhamento do contexto social e ambiental em que estas exposições ocorrem. Para tanto, faz-se necessário a realização de uma vigilância efetiva dessas áreas, sendo 
imprescindível a integração entre setores, no cuidado à saúde das populações a riscos ambientais (Ministério da Saúde, 2010).

Em 2004, o Ministério da Saúde criou o Programa de Vigilância em Saúde das Populações Expostas a Solo Contaminado (VIGISOLO) com o justo objetivo de programar atividades sobre a prevenção e o controle da exposição a solos contaminados (Fernandes et al., 2016). Tal estratégia vem executada em alguns municípios brasileiros sob a responsabilidade da Vigilância em Saúde Ambiental local.

Além disso, os principais objetivos secundários do programa estão centralizados em: avaliar riscos, protocolos, priorizar áreas com populações expostas, coordenar ações intrasetoriais, mobilização social, desenvolver estudos e pesquisas.

De forma atualizada, há um modelo estruturante para o fluxo de atuação atualmente estabelecido pelo programa e vem estabelecendo etapas para nortear as ações, uma vez que as situações de exposição humana a contaminantes químicos são específicas, tendo determinantes próprios, devendo ser analisados caso a caso. Podem ser adotadas duas formas de conduta, que podem ser concomitantes e não exclusivas, proativa e reativa.

A procedência proativa liga-se à antecipação ao problema, com foco em prevenir os impactos negativos que possam existir nas áreas, priorizando promover bons índices em saúde da população que, porventura, está potencialmente exposta.

Já na reativa há uma questão contrária. Após uma problemática já está instalada, bem como, o manifesto de suas consequências, ocorre o desenvolvimento de uma ação por parte das populações através das denúncias para os órgãos competentes. Neste caso, são adotadas medidas para minimizar os impactos, melhorando a qualidade de vida da população exposta, da qual, futuramente será acompanhada através de outros indicadores mais específicos.

Portanto, cada vez mais que se realizarem levantamentos que possibilitem conhecer os aspectos que vão direcionar um determinado grupo social a altos níveis de vulnerabilidade serão de extrema importância para formular políticas públicas.

Segundo Deschamps (2004) as populações situadas em situações de vulnerabilidade ambiental/social altas coexistem com espaços naturais susceptíveis aos eventos naturais adversos. Tais áreas geralmente são habitadas por indivíduos e famílias que não possuem recursos de qualquer natureza para responderem adequadamente à ocorrência de um evento natural perigoso. Sendo a atuação de órgãos públicos uma ferramenta imprescindível.

Jackson Filho et al. (2018) destacam que outro requisito fundamental a ser incorporado é o foco e o alcance da intervenção aplicada, uma vez que esta ocorre ou influencia situações e processos de trabalho que são, por natureza, obje envolvendo pessoas, modos de organização e gestão, instrumentos e equipamentos em atividade conjunta, a qual sofre influências externas (de outras empresas e instituições, do mercado financeiro, do movimento sindical, ambiental, entre outras) e pode causar impactos no ambiente e comunidade.

Diante disso, o objetivo do estudo foi identificar áreas localizadas no município de Sobral-Ceará, das quais, possuem risco de contaminação por compostos químicos em populações residentes de suas proximidades, representadas pela atividade de revenda de combustíveis. Adicionalmente, realizar um diagnóstico da saúde ocupacional dos trabalhadores dos estabelecimentos.

\section{Materiais e métodos}

\section{Área de estudo}

A pesquisa foi desenvolvida no território de Sobral, interior norte do Estado do Ceará. De acordo com o IBGE (2018), o município tem uma população estimada em 
206.644 habitantes, tendo uma área territorial de $2.122,897 \mathrm{~km}^{2}$, localizado aproximadamente a $240 \mathrm{~km}$ de distância da capital Fortaleza. Na estrutura urbana é composta oficialmente por 17 unidades distritais (Aprazível, Aracatiaçu, Baracho, Bilheira, Bonfim, Caioca, Caracará, Jaibaras, Jordão, Patos, Patriarca, Pedra de Fogo, Rafael Arruda, São José do Torto, Salgado Dos Machados, São Francisco e Taperuaba), sendo compartimentada em 37 bairros.

O seu Índice de Desenvolvimento Humano Municipal (IDHM) é de 0,714, valor considerado alto. Possui o maior Produto Interno Bruto (PIB) da Região Norte do Ceará, capitaneado pelo setor industrial e de serviços, constituindo-se como polo centralizador da região (Gomes e De Paula, 2019).

Em relação aos principais dados direcionados aos indicadores em saneamento básico: o índice de atendimento total de água (incluindo população urbana e rural) do município está em 99,97\%, para o esgoto o índice da parcela populacional urbana com atendimento por rede coletora é de $94,82 \%$, com taxa de tratamento em $49,11 \%$. Os resíduos sólidos possuem uma taxa de $100 \%$ em cobertura do serviço de coleta; há um equivalente médio quantitativo de produção de $2,85 \mathrm{~kg} / \mathrm{hab} /$ dia (Snis, 2019).

Na Figura 1 é possível observar a localização geográfica do Município de Sobral, frente a sua disposição na Região Nordeste e diante do território no Estado do Ceará.

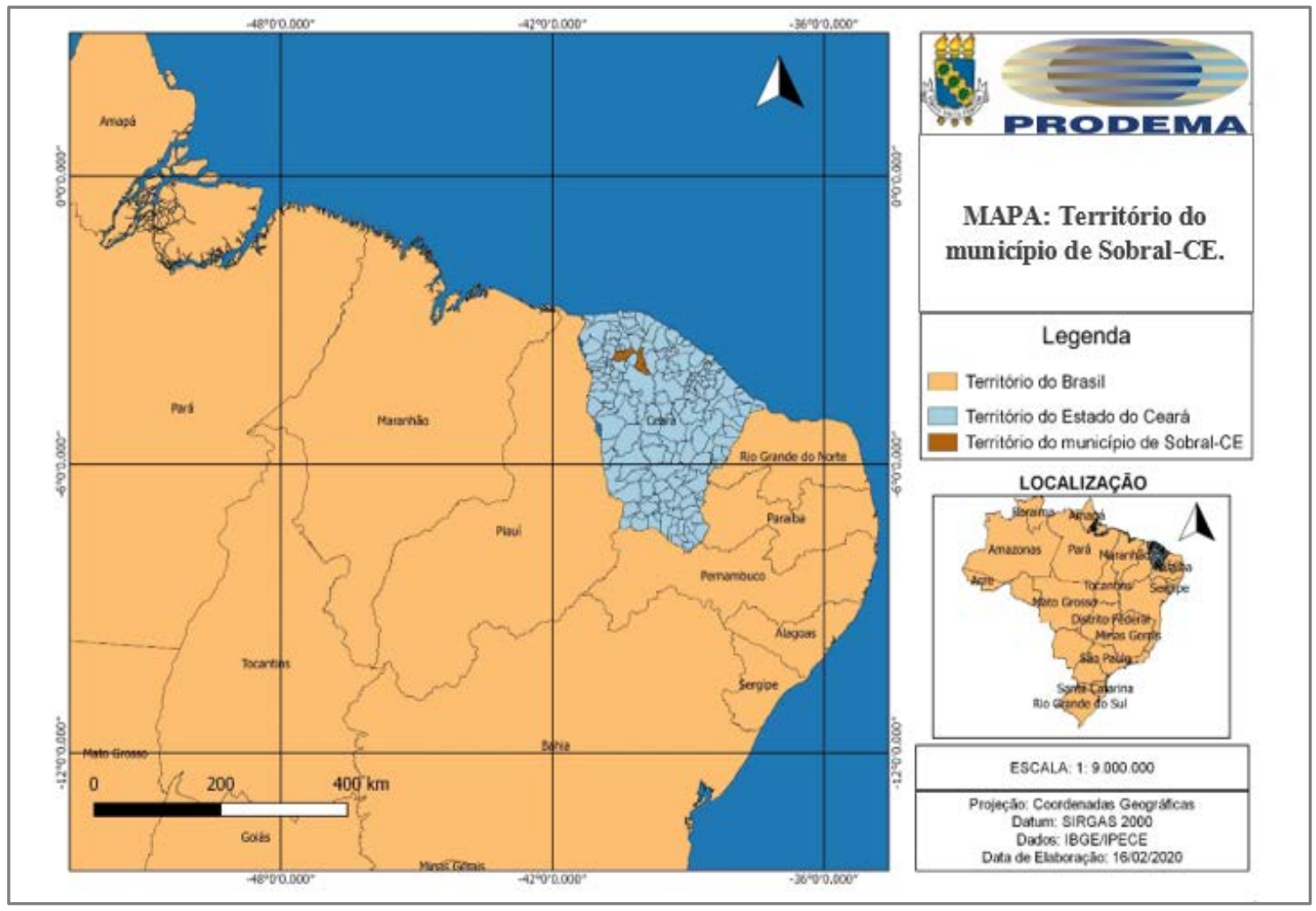

Figura 1. Localização geográfica do Município de Sobral-CE.

A seleção dos pontos de monitoramento foi direcionada aos espaços que apresentavam riscos de contaminação específica, no caso, os postos distribuidores de combustíveis cadastrados e registrados no território do município. 
Primeiramente, foram realizadas pesquisas nos diversos órgãos de fiscalização e responsáveis pela regulação da atividade de distribuição de combustíveis e seus derivados, levando em consideração primordialmente o que estava pontuado pela Agência Nacional de Petróleo, Gás Natural e Biocombustíveis (ANP). Além disso, os registros na Superintendência Estadual do Meio Ambiente (SEMACE) também foram consultados.

Assim sendo, foi constatado a existência de 70 postos de combustíveis instalados no Município de Sobral (sede e distritos). De posse desse dado, todas as demais informações foram buscadas endereço, CNPJ, responsável pelo estabelecimento e contatos gerais, para que fossem formuladas equipes e assim iniciar as atividades de campo para realização dos questionamentos obrigatórios na ficha de campo liberada pelo Ministério da Saúde e assim poder traçar um delineamento ou não de risco das populações no entorno destes estabelecimentos e, porventura, planejar ações de vigilância em saúde comunitária. Do total citado anteriormente, apenas 38 postos estavam aptos a serem analisados, pois 32 deles encontravam-se desativados.

\section{Procedimentos metodológicos}

Trata-se de estudo descritivo, exploratório, quali-quantitativo, cuja principal unidade de análise é a organização em saúde ambiental dos postos revendedores de combustíveis em todo território do município, com marco de estudo de caso.

As ações de acompanhamento foram baseadas em vistorias técnicas realizadas ao longo dos anos de 2018 e 2019. De forma a contextualizar, foram realizadas extensas buscas bibliográficas, tendo as seguintes palavras-chave como orientação, "contaminação", "riscos", "vulnerabilidade", "compostos químicos" e "saúde pública".

0 instrumento metodológico adotado seguiu o modelo de condução das informações de campo in loco, denominado de Ficha de campo Vigissolo, do qual, foram compostos por questionamentos objetivos e subjetivos (totalizando 40 itens). Foram preenchidos com informações oriundas de um levantamento prévio junto às instituições que possuíam o cadastro ambiental dos estabelecimentos, principalmente órgãos ambientais, além do reconhecimento da área, validação e complementação de informações para uma caracterização inicial da situação. Os respondentes foram os representantes da empresa (gerentes ou proprietários), que após tomarem conhecimento do estudo, aceitaram voluntariamente em responder as perguntas.

Além do referido preenchimento que estava baseado em informações cedidas pelos proprietários, estavam complementadas com registros fotográficos, dentre outras anotações pertinentes.

Todas as solicitações da ficha foram obrigatórias no tocante ao seu preenchimento no momento do campo, bem como, também foram informados ao Ministério da Saúde por intermédio do sistema de informação SISSOLO, portanto, quando não havia dados para determinado campo ele era preenchido com um traço (-). É importante salientar que os departamentos em saúde utilizam com bastante frequência sistemas de informação para sistematização de seus dados e assim poder traçar um perfil situacional das áreas em que são investigadas. De posse da consolidação dos resultados é possível com maior facilidade tomar decisões frente a fragilidades ou vulnerabilidades detectadas. Na Figura 2, ilustra-se a interface do sistema.

Em sua grande maioria, os sistemas são de acesso restrito aos servidores em saúde, que possuem cadastros previamente autorizados pelo Ministério da Saúde ou algum outro departamento local. 


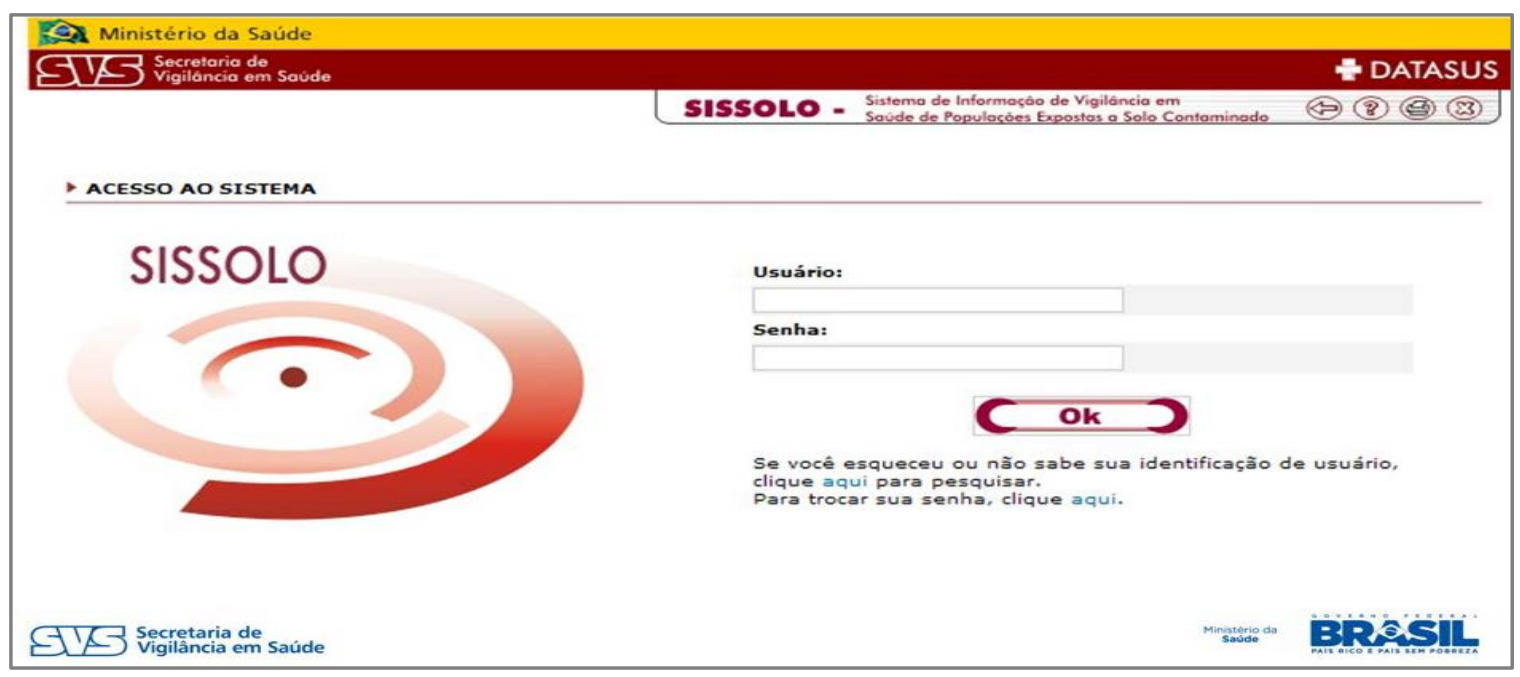

Figura 2. Interface do sistema de informação SISSOLO. Fonte: Ministério da Saúde (2017).

É importante destacar que as visitas de campo para preenchimentos e acompanhamentos não teve caráter de fiscalização pela perspectiva punitiva do empreendimento instalado na área a ser identificada, mas principalmente, realizar uma caracterização inicial do seu entorno, considerando aspectos de interesse para a saúde pública no território municipal.

\section{Resultados e discussão}

Os postos revendedores de combustível podem ser classificados em duas categorias: postos cidade e postos estrada, variando em função das atividades neles aplicadas. 0 primeiro é direcionado para atender às necessidades da população urbana, enquanto o segundo está conduzido a atender às necessidades dos viajantes e dos caminhoneiros. Isso reflete diretamente na localização territorial do estabelecimento, enquanto o primeiro está prioritariamente em perímetro urbano e possui estruturas menores, o segundo concentra-se geralmente junto às estradas e possui uma estrutura relativamente maior em função de outros serviços ofertados (estacionamentos, banheiros, locais para alimentação, lojas para vendas de outros produtos) (Santos, 2005).

0 setor de distribuição e revenda de combustíveis é considerado como uma atividade de grande potencial poluidor do meio ambiente, pois além de poluir o ar, sem as medidas necessárias poderá contaminar as águas e o solo e vem investindo em proteção ambiental e buscando adequar-se as legislações ambientais existentes, para assegurar que essa atividade não agrida o meio ambiente (Lorenzetti e Rossato, 2010).

Da mesma forma, verifica-se o aumento da quantidade de áreas contaminadas decorrentes desse tipo de atividade, como consta nos inventários efetuados por órgãos ambientais de alguns Estados brasileiros, como São Paulo e Minas Gerais, que possuem há mais tempo o gerenciamento de áreas contaminadas (CETESB, 2014; Minas Gerais, 2015). Este aumento pode estar associado à promulgação de muitos instrumentos normativos ao longo dos anos, dos quais, puderam apresentar subsídios para realização de cada vez mais análises ambientais.

Os poluentes gerados nesses espaços ao serem introduzidos no meio ambiente e dependendo de suas características físico-químicas, bem como, o nível de periculosidade e toxicidade tendem a ser transportados pelas correntes atmosféricas ou águas superficiais 
e subterrâneas, podendo resultar em impactos ambientais de difícil mitigação (Balkis et al., 2012; Balseiro-Romero et al., 2016).

Ao levantamento das substâncias químicas existentes nas áreas analisadas, identificou-se que havia presença e manipulação de compostos contaminantes potenciais, tais como: BTEX (benzeno, tolueno, etil-benzeno e xilenos), metais pesados, fenóis, COV (compostos orgânicos voláteis) e HTP (hidrocarbonetos totais de petróleo).

Segundo Moraes e Oliva (2019) ao investigarem a possível presença de compostos destas categorias na região do Estado do Pará e em áreas próximas a postos de combustíveis da região, constataram que entre os pontos monitorados, todos indicaram existência de vazamentos de hidrocarbonetos na subsuperfície e com notória atenuação natural dos BTEX no subsolo.

No prosseguimento do estudo, identificou-se que 95\% deles apresentaram populações em suas proximidades alcançando um raio de até $1 \mathrm{~km}$, com distribuição populacional variada (meio urbano apresentou um maior número e no meio rural um menor), trabalhadores com faixas-etárias distintas (variação entre 18 e 60 anos). Em relação as classes sociais identificadas mostraram-se entre classe média e baixa. Apenas em $5 \%$ dos estabelecimentos não foram encontradas presença populacionais.

Cerca de $60 \%$ dos postos de combustíveis contavam com a existência de algum curso d'água nas redondezas (rios, riachos), portanto, sendo necessário um estudo futuro mais detalhado para averiguar se de fato não está ocorrendo nenhum tipo de poluição/contaminação, uma vez que pequenos vazamentos podem infiltrar no solo, atingindo concentrações de águas subterrâneas e até mesmo corpos d'água superficiais. Em relação à fonte de abastecimento de água, 92\% são abastecidos por algum tipo de sistema de água potável, seja ela por rede convencional de distribuição ou por meio de soluções alternativas (poços ou cisternas).

Em relação à regularização das licenças ambientais, obrigatoriamente emitidas pela Superintendência Estadual do Meio Ambiente (SEMACE), o perfil constatado consistiu na seguinte situação, $100 \%$ tinham licença de operação (LO), inclusive com a placa publicitária, localizadas em sua grande maioria nos ambientes externos. Havia divulgação dos números nos processos, prazos e profissionais responsáveis. Contudo, 80\% estavam com seu prazo de vigência vencido. Foi argumentado que novos protocolos de renovações estavam em andamento, porém, a carência de técnicos na superintendência não possibilitou a finalização das ações.

As estratégias sugeridas pelos órgãos ambientais através das vistorias periódicas a serem realizadas após a emissão da licença ambiental, tem ainda a finalidade adicional de coibir infrações relacionadas a danos ou ineficiência de equipamentos instalados e a destinação inadequada de resíduos da classe I (perigosos). Além disso, haverá a uniformização de todo processo de forma contínua (Silva e Souza, 2020).

Em relação à disposição e armazenamento das embalagens resultantes das trocas e separações de óleo veicular, que de acordo com a legislação não podem ser simplesmente liberadas na rede pública para coleta convencional de resíduos e de esgoto sanitário, constatou-se que $85 \%$ realizam a coleta adequada em recipientes apropriados para tal finalidade, sendo entregues a empresas especializadas para a coleta. Foi pontuada uma regularidade de três em três meses ou conforme a demanda para a atividade. Os outros $15 \%$ restantes (grande parte na zona rural) não realizavam coleta adequada e descreveram que o descarte é feito através da coleta de resíduos convencional. Para esta as unidades dentro desta situação devem ser realizadas uma profunda campanha para orientar os responsáveis e demais envolvidos.

Apenas um estabelecimento argumentou a prática de atividades relacionadas à coleta seletiva dos demais resíduos que são produzidos, salientando que, todos os colaboradores são orientados a realizar o processo de separação, bem como os clientes também. A realização do processo auxilia os trabalhadores da limpeza pública urbana, 
minimizando os processos de futuras contaminações tanto no solo, quanto na população das áreas próximas.

Para a gestão dos resíduos sólidos e líquidos produzidos nestes estabelecimentos um requisito fundamental está em elaborar o plano de gerenciamento; documento que faz o detalhamento de todos os tipos de materiais gerados, classificações necessárias e, consequentemente, traz uma explicação de como o estabelecimento está promovendo o acondicionamento, destacando sua destinação final. Com isso organizado, auxiliará na condução correta pelos funcionários destes materiais de modo a não propiciar impactos ou alterações ambientais indesejáveis.

Na Figura 3, observa-se a consolidação dos principais resultados alcançados com o desenvolvimento do estudo em relação aos postos de combustíveis juntamente com as variáveis investigadas.

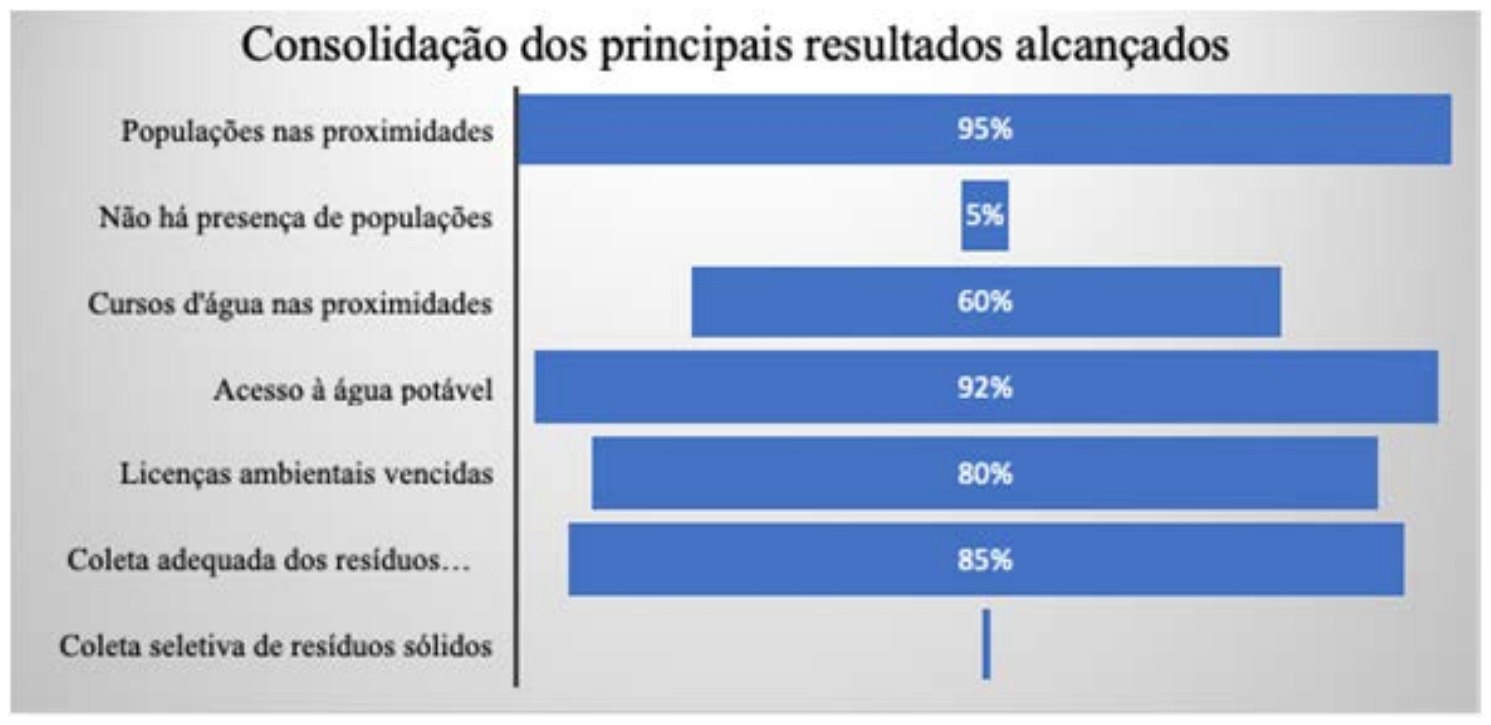

Figura 3. Representação dos principais resultados encontrados no estudo.

Em pesquisa conduzida por Rodrigues (2015) no Município de São Paulo, foi constatado que a presença dos postos de combustíveis em áreas em que não havia o monitoramento regular dos órgãos de fiscalização e de saúde ambiental estiveram classificados com "baixa segurança" de operação. Além deste fator, a avaliação destacou que havia necessidade imediata de alertar a população quanto ao risco de instalar poços de captação de águas subterrâneas clandestinamente nos perímetros onde há ativação desta atividade, caso contrário, haverá uma notória probabilidade de risco à saúde quanto aos efeitos tóxicos das substâncias químicas, principalmente ocasionados pela gasolina.

De forma a complementar todos os levantamentos, o Centro Regional de Referência em Saúde do Trabalhador (CEREST) do Município de Sobral realizou acompanhamento e delineamento da realidade dos postos de combustíveis no tocante ao estado de saúde e segurança ocupacional, níveis de exposição e possíveis contaminações dos funcionários. Tais questões, foram conduzidas com fichas internas de investigação.

A função de frentista expõe o trabalhador a inúmeros tipos de riscos pré existentes em seu ambiente de trabalho, podendo se destacar, dentre eles, o risco físico: com a presença de ruído, a exposição a calor e chuvas, ou quaisquer variações do tempo devido ao seu ambiente de trabalho ser aberto; 0 risco químico: com o contato de produtos 
químicos e seus derivados durante todo o seu expediente; 0 risco ergonômico: com a repetitividade dos seus movimentos ou possíveis problema nas bombas de abastecimento, exigindo uma força ou movimento maior do que necessário, gerando eventuais problemas físicos. Além disso, há a constante presença do risco por acidente de trabalho e agravantes externos como assaltos ou possíveis atropelamentos (Lima et al., 2008).

0 estudo sobre o risco do benzeno foi dividido em três parâmetros: monitoramento da exposição, controle das operações e higienização. Os principais resultados consideraram que: há exposição perigosa ao benzeno dentre os 38 postos pesquisados, apenas um realizou e comprovou que seus trabalhadores foram capacitados quanto aos riscos associados; três monitoravam os trabalhadores através do exame de hemograma completo; e o quantitativo restante, 34, não apresentou nenhum registro.

0 controle do benzeno no ambiente, bem como, na realização das atividades, instrução do trabalhador e vigilância da saúde ainda não são colocados em prática na maioria dos estabelecimentos. 0 diagnóstico de benzenismo, de natureza ocupacional, é eminentemente clínico epidemiológico fundamentando-se na história de exposição ocupacional e na observação de sintomas e sinais clínicos e laboratoriais. 0 trabalhador deve passar por exames periódicos, realizando hemograma completo semestralmente.

Sobre a sinalização acerca da presença do benzeno, verificou-se que em apenas $43 \%$ dos postos pesquisados havia sinalizações, o que representa ainda um índice baixo do ponto de vista da sensibilização dos pessoais quanto ao agente nocivo e os meios de prevenção. A NR 9 do MTE (Brasil, 1978) preconiza que todos devem manter a sinalização, em local visível, na altura das bombas de abastecimento de combustíveis líquidos contendo o benzeno, indicando os riscos, nas dimensões de $20 \times 14 \mathrm{~cm}$ com os dizeres: "A GASOLINA CONTÉM BENZENO, SUBSTÂNCIA CANCERÍGENA. RISCO À SAÚDE!”.

Apesar de não haver obrigatoriedade legal nestes locais de distribuição de combustível sobre o monitoramento ambiental do benzeno, entende-se como imprescindível essa avaliação para averiguar a concentração de toxicidade da substância no ambiente a fim de servir como indicador com implantação de sistemas de proteção individual ou coletiva, visando unicamente à saúde dos trabalhadores expostos.

Quanto à aplicação de novas tecnologias para monitoramento eletrônico dos tanques e sistemas de captação de vapores, nenhum dos postos combustíveis apresentou evidências, assim como desconhecem essas aplicações. Esses tipos de sistemas além de auxiliar a diminuição da concentração de vapores orgânicos nos ambientes, também geram economia ao estabelecimento evitando que o combustível em forma de vapor se dissipe para a atmosfera e seja conduzido de volta aos tanques, estando previsto também na NR 09 do MTE (Ministério do Trabalho). E as medições dos referidos tanques, que atualmente ocorre manualmente, levando o trabalhador ao contato com o vapor durante as aberturas das portas de visita, podem ser acompanhados através de sistemas eletrônicos que forneciam a leitura interna do nível do líquido no reservatório.

A disponibilização dos equipamentos de proteção individual (EPI's) e sua obrigatória higienização prevista na NR 06 do MTE (Brasil, 1978), apenas 14 estabelecimentos apresentaram evidências da entrega dos equipamentos e dois relataram que se responsabilizam pelas suas respectivas limpezas. Devido ao contato permanente com o benzeno, o EPI precisa ser higienizado frequentemente, caso contrário, passa a ser um agente contaminador quando o trabalhador veste ou retira, sendo o contato com os dedos o meio ativo de contaminação. Em fase aos possíveis respingos e acidentes envolvendo o derramamento de combustíveis na roupa do trabalhador, foi questionado sobre a disponibilidade de fardamento extra onde apenas $27 \%$ dos locais afirmaram dispor no local para essa finalidade. Ainda sobre esses possíveis acidentes, e nenhum possuía de lava-olhos para emergências em caso de contato com as substâncias na região ocular. 
Baseado nos riscos ocupacionais relatados pelo CEREST do Município de Sobral, foi recomendado que as empresas observassem as determinações previstas nas Normas Regulamentadoras do MTE e as Normas Brasileiras em vigência. Contudo, considerando as medidas de urgência, foi citado: execução de seminários para ações de sensibilização aos proprietários dos postos de combustíveis, bem como aos seus trabalhadores. Sobre os riscos de a exposição ao benzeno intensificar de forma mais eficiente todo 0 acompanhamento.

Com uma análise similar ao presente estudo, o CEREST com sede no município de Santa Cruz do Sul, cidade localizada no Estado do Rio Grande do Sul, que tem uma abrangência de atuação em 68 municípios, evidenciou que dos 297 estabelecimentos registrados como comércio varejista de combustíveis para veículos automotores e monitorados na região, havia o registro de 13 acidentes e doenças relacionadas ao trabalho e que mais de 1.500 exames foram relacionados em trabalhadores para fins de monitoramento da saúde (Skamvetsakis et al., 2017).

Um levantamento realizado pela Clínica de Fonoaudiologia da Faculdade de Odontologia de Bauru da Universidade de São Paulo para verificar os níveis de saúde e ocorrência de sintomas característicos em 35 participantes trabalhadores de postos de combustíveis nos últimos 12 meses, mostraram que os sintomas mais prevalentes foram dores em pescoço/coluna cervical e quadril (em 55\% dos questionados), seguidos de incômodos na região lombar (em 50\%); constatou-se alterações auditivas dos profissionais, indicando ação tóxica da exposição a combustíveis. 0 que deve ser mostrado que todos esses resultados poderiam ter sido evitados se programas e medidas de ergonomia do trabalho e exigência de exames regulares fossem exigidos e acompanhados pelos órgãos de orientação do trabalho e de saúde local; essas evidências propiciam a importância da vigilância junto a esses níveis de exposição (Prestes, 2017).

Por fim, observa-se que ao longo dos anos, houve uma notória evolução na maneira de tratar a saúde dos trabalhadores no Brasil, porém, ainda existem desafios e isso inclui uma maior participação dos próprios trabalhadores, pois na prática, muitos negam a existência de contaminação ou presença de riscos; é importante que sejam feitos levantamentos quantitativos e que as informações alcançadas sejam consolidadas e transformadas em políticas públicas, evitando o adoecimento dos trabalhadores (Costa e Goldbaum, 2017).

\section{Conclusão}

Conclui-se que o programa federal de vigilância em saúde ambiental VIGISOLO constitui-se de um instrumento adequado para a identificação de áreas, das quais, podem tornar as populações expostas a algum potencial contaminante.

No caso da pesquisa, foram analisados todos os postos de revenda de combustíveis devidamente registrados no Município de Sobral (sede e distritos), conhecendo o nível de exposição das comunidades e populações residentes no raio de até $1 \mathrm{~km}$ destes estabelecimentos, que foi tratado no final das análises como suspeito.

Notou-se, que há riscos de possíveis processos de contaminação nos recursos hídricos presentes, nas proximidades da grande maioria dos estabelecimentos avaliados; muitos dos postos estão com as licenças operacionais emitidas pelo órgão ambiental de fiscalização vencido, portanto, necessitando de regularização imediata. Os que fazem o serviço de troca de óleo em veículos mantêm contrato ativo com empresas especializadas para o recolhimento, tanto do líquido residual, quanto das embalagens.

E de forma a complementar o trabalho de vigilância, o CEREST do Município de Sobral também atuou como órgão conhecedor dos graus de exposição ocupacional dos trabalhadores destes locais, sendo de fundamental relevância para complementação do diagnóstico. Os levantamentos realizados identificaram a exposição suspeita de benzeno, 
sendo que, a grande maioria dos empregadores não realizam os exames cotidianos obrigatórios dos funcionários e a distribuição dos equipamentos de proteção individual necessitam ser melhorada.

Os resultados alcançados pelo programa podem ser direcionados a outras instituições de saúde, tais como, unidades básicas de saúde; que em alinhamento conjunto com à Vigilância em Saúde do Município poderão elaborar programas e estratégias locais para um melhor acompanhamento e tomada de decisão assertivas.

Para discussões futuras é necessário estimular outras ações intersetoriais não somente com a vigilância ambiental e saúde do trabalhador, mas também pela vigilância epidemiológica, vigilância sanitária, atenção básica de saúde, laboratórios de saúde pública, instituições de ensino e pesquisa, dos quais, também possam representar um perfil de avaliação mais consistente. É reiterada a relevância de estender os processos de identificação para outras áreas existentes no espaço urbano, assim como: cemitérios, aterros sanitários e até mesmo empresas de alto potencial de impacto ambiental e social, monitorando por completo essas áreas.

\section{Agradecimentos}

Os autores agradecem à Prefeitura Municipal de Sobral, em especial à sua Secretaria Municipal de Saúde, bem como, seus núcleos de Vigilância em Saúde Ambiental (VISAM) e Vigilância em Saúde do Trabalhador (CEREST) pelo apoio no desenvolvimento do estudo. À Coordenação de Aperfeiçoamento de Pessoal de Nível Superior (CAPES) pelo incentivo a pesquisa.

\section{Conflito de interesses}

Os autores declaram não haver conflito de interesses.

\section{Referências}

Balkis, N.; Aksu, A.; Ersan, M. Petroleum hydrocarbon contamination of the Southern Black Sea Self, Turkey. Environmental Science and Pollution Research, v. 19, n. 2, p.592-599, 2012. http://doi.org/10.1007/s11356-011-0583-4

Balseiro-Romero, M.; Macías, F.; Monterroso, C. Characterization and fingerprinting of soil and groundwater contamination sources around a fuel distribution station in Galicia (NW Spain). Environmental Monitpring and Assessment, v. 188, n. 5, p. 1-15, 2016. http://doi.org/10.1007/s10661-016-5288-1

Brasil. Ministério do Trabalho. NR 09-Avaliação e controle das exposições ocupacionais a agentes físicos, químicos e biológicos. Brasília: MTE, 1978. Disponível em: <https://www.gov.br/trabalho/pt-br/inspecao/seguranca-e-saude-no-trabalho/ normas-regulamentadoras/nr-09-atualizada-2020.pdf>. Acesso em: 10 jun. 2021.

Brasil. Ministério do Trabalho. NR 6 - Equipamento de Proteção Individual - EPI. Brasília: MTE, 1978. Disponível em: <https://www.gov.br/trabalho/pt$\mathrm{br} /$ inspecao/seguranca-e-saude-no-trabalho/normas-regulamentadoras/nr-06.pdf $>$. Acesso em: 10 jun. 2021.

CETESB - Companhia Ambiental do Estado de São Paulo. Relação de áreas contaminadas e reabilitadas no Estado de São Paulo. São Paulo: CETESB, 2014.

Deschamps, M. V. Vulnerabilidade socioambiental na Região Metropolitana de Curitiba. Curitiba: UFPR, 2004. (Tese de doutorado). 
Fernandes, L. O.; Nunes, J. 0.; Porto, M. F. S. Contaminação química: respostas das instituições responsáveis e ações das populações atingidas no Brasil e em Portugal. Revista Saúde Sociedade, v. 25, n. 1, p. 218-232, 2016. https://doi.org/10.1590/S010412902016145753

Gomes, F. B. M.; De Paula, D. P. Os efeitos da sazonalidade climática e da urbanização na qualidade das águas do Rio Acaraú em Sobral (CE). Revista Caminhos de Geografia, v. 20, p. 421-436, 2019. http://doi.org/10.14393/RCG206941479

Jackson Filho, J. M.; Pina, J. A.; Vilela, R. G. A.; Souza, K. R. Desafios para a intervenção em saúde do trabalhador. Revista Brasileira de Saúde Ocupacional, v. 43, n. 13, p. 1-7, 2018. https://doi.org/10.1590/2317-6369AP0141218

IBGE - Instituto Brasileiro de Geografia e Estatística. Panorama de cidades brasileiras (pesquisas, histórias e fatos). Disponível em: <https://cidades.ibge.gov.br/brasil/ ce/sobral/panorama>. Acesso em: 11 jan. 2018.

Lorenzetti, D. B.; Rossato, M. V. A gestão de resíduos em postos de abastecimento de $\begin{array}{llllll}\text { combustível. Revista Gestão Industrial, } & \text { v. 6, } & \text { n. 2, } & \text { p. 110-125, } 2010 .\end{array}$ https://doi.org/10.3895/S1808-04482010000200006

Minas Gerais. Inventário de áreas contaminadas do Estado de Minas Gerais. Belo Horizonte: Fundação Estadual do Meio Ambiente, 2015.

Ministério da Saúde. Diretrizes para a priorização de áreas com populações sob risco de exposição a contaminantes químicos. Brasília: Ministério da Saúde, 2010. Disponível em: <http://www.rio.rj.gov.br/dlstatic/10112/9720718/4239904/DIRETRIZESPARAA PRIORIZACAODEAREASCOMPOPULACOES.pdf>. Acesso em: 15 mar. 2018.

Ministério da Saúde. Vigisolo, modelos de atuação e principais ações. 2017. Disponível em: <https://antigo.saude.gov.br/vigilancia-em-saude/vigilancia-ambiental/vigipeq/ vigisolo>. Acesso em: 11 jan. 2018.

Moraes, Y. G.; Oliva, P. C. Estudo integrado para identificação por hidrocarbonetos na subsuperfície de postos de combustíveis no município de Baião (Pará, Brasil). Brazilian Journal of Development, v. 5, n. 12, p. 30252-30271, 2019. https://doi.org/10.34117/ bjdv5n12-153

Prestes, S. C. C. Análise da qualidade de vida e prevalência de dores musculares em trabalhadores de postos de combustível. São Paulo: Universidade de São Paulo, 2017. (Tese de doutorado).

Rodrigues, G. M. A. Atividade de armazenamento e distribuição de combustível nos centros urbanos: os postos de combustíveis e a saúde pública. São Paulo: Universidade de São Paulo, 2015. (Dissertação de mestrado).

Santos, R. J. S. A gestão ambiental em posto revendedor de combustíveis como instrumento de prevenção de passivos ambientais. Rio de Janeiro: Universidade Federal Fluminense, 2005. (Dissertação de mestrado).

Silva, V. P.; Souza, S. K. S. Caracterização ambiental de posto de revenda de combustíveis sob a ótica de adequação ambiental. Research, Society and Development, v. 9, n. 7, e368973527, 2020. https://doi.org/10.33448/rsd-v9i7.3527

Skamvetsakis, A.; Santi, R.; Rocha, L. H. P.; Brettas, F. Z.; Fagundes, P. S.; Correa, M. J. M. Exposição ao benzeno em postos de combustíveis: estratégia de ações integradas de Vigilância em Saúde do Trabalhador na região dos Vales/RS. Revista Brasileira de Saúde Ocupacional, v. 42, n. 1, p. 1-11, 2017. https://doi.org/10.1590/2317-6369000126015 
SNIS - Sistema nacional de Informações sobre Saneamento. Painel de informações sobre saneamento. 2019. Disponível em: <http://appsnis.mdr.gov.br/indicadores/web/>. Acesso em: 10 jun. 2021.

CC Informação da Licença: Este é um artigo Open Access distribuído sob os termos da Licença Creative Commons Attribution, que permite uso irrestrito, distribuição e reprodução em qualquer meio, desde que a obra original seja devidamente citada.

Rev. Bras. Gest. Amb. Sustent., 2021, vol. 8, n. 19, p. 1061-1073. 